\section{Human experimentation}

\section{Indian rules}

\section{Lucknow}

To help Indian investigators plan their clinical studies the Indian Council of Medical Research (ICMR) has formulated guidelines for conducting medical research on human subjects.

The guidelines have been prepared by the ICMR Central Ethical Committee whose chairman is a legal expert and whose members include the Drugs Controller of India. Briefly, they seek to ensure that the rights and welfare of subjects participating in a trial are protected, that the benefits accruing from the research outweigh the risks to the individual, that the "informed consent" of the subject is obtained before the start of the trial, and that the investigator has the competence and experience to conduct the trial.

ICMR has forwarded the guidelines to the Indian government and hopes that they will be followed by all institutions engaged in clinical research in the country. Institutions under the aegis of ICMR have already been instructed to follow the guidelines. It is suggested that, to implement the new code, each institution conducting clinical research should form its own committee, which would consist of five to seven experienced clinicians and nonmedical persons able to give advice on legal and ethical matters. These committees would then evaluate each proposal for research on human subjects by following a nine-point code. ICMR recommends that, if the ethical committees are to be effective, they should be independent bodies.

Recognizing that it may take some time for each institution to form its own committee, ICMR has offered to provide the services of an ethical committee to evaluate projects during an interim period of one year. This new role for ICMR will enable Indian institutions which do not have ethical committees to apply for funds from international agencies such as the World Health Organization, which will not consider a proposal for research support unless approved by an ethical committee.

The ICMR guidelines stress the importance of obtaining the informed consent of each subject. Although the details for obtaining consent are left to individual committees to work out, ICMR insists that the subject or his guardian should be given as much information as possible about the drug to be studied, including its side effects, and that it should be made clear to him that he is free to refuse to take part in the trial.

Indian law demands that the permission of the Drugs Controller of India is obtained before a clinical trial is performed on a new drug. ICMR proposes to hold meetings with other organizations involved in clinical research, to formulate ethical safeguards that will prove generally acceptable.

Zaka Imam
Vitamin deficiencies

\section{Rickets at bay}

Vitamin D-deficiency rickets appears to be on the decline among Britain's Asian community. The Department of Health and Social Security last week reported* a fall in the incidence of rickets among Asian children in the past ten years, but says that the disease remains a problem. Seeking to eradicate the disease, a department working party recommends vitamin D supplements for children at risk rather than the fortification of specific foods, milk or chapatti flour.

Once known as the "English disease", rickets was common in Victorian England with as many as a half of the children in poor areas in Leeds said to be suffering from it at the end of the nineteenth century. In the period 1926-42, the incidence was still high, with some 2-8 per cent of children in British cities with the condition. During the Second World War, however, rickets was almost eradicated by a programme (begun in 1943) in which all children received vitamin $D$ in the form of cod liver oil supplements. The hope now is that the same approach could work among Asian children now at risk.

Rickets and its adult equivalent, osteomalacia, were first documented as a serious problem in the Asian community in Glasgow in the early 1960 s, and since then has been observed in most of the larger Asian communities in the United Kingdom. Neither disease is notifiable, however, and data collection is not easy.

The recent decline of incidence is suggested by figures from the Hospital InPatients Enquiry Programme and from a survey involving 130 general practitioners in areas with large immigrant populations. In 1977, in the Midlands and north of England, ten Asian children in 1,000 under the age of 16 had rickets, compared with only four per 1,000 in London. The risk factors are said to be lack of sunlight, strict vegetarian diet, poor rural background and a family history of rickets or osteomalacia. As both bone diseases are common in the Indian subcontinent, the report suggests that immigrants may bring it with them.

Thus, the department says, it should not be difficult to identify those at risk, which is why its report recommends vitamin D supplements backed up by health education. The decision against food fortification has been recommended by the department's Committee on Medical Aspects of Food Policy, which has studied the problem for four years, but will not satisfy all clinicians responsible for treating rickets in the Asian community.

The case for the more radical programme of fortifying specific target *Rickets and osteomalacia. Report of the Working Party on fortification of food with vitamin D, Committee on Medical Aspects of Food Policy, Department of Health and Social Security. HMSO, $£ 3.90$. foods has fallen because legislation would be required before vitamin $\mathrm{D}$ could be added to specific foods such as milk or flour, and because the food policy committee has argued that there are sound medical reasons for not taking such a course. Thus there might then be excess vitamin consumption and, as a consequence, the risk of hypercalcaemia in children and possibly of cardiovascular complaints in adults.

In retrospect, the hypercalcaemia observed in young infants in Britain in the 1950 s was almost certainly due to vitamin D overdosing. The department's report says that if milk were to be fortified with vitamin $\mathrm{D}$, some children could well receive too much, especially if concerned parents also choose to provide vitamin supplements.

Technical problems complicate the fortification of chapatti flour - the target food best suited to the needs of the Asian community in Britain. Although vitamin D is stable in the flour, up to 50 per cent can be destroyed in cooking. Choosing the correct amount to add to flour is therefore difficult and the concentration of vitamin D needed to prevent rickets in young children might well prove a health risk to teenagers and adults.

Alastair Hay

\section{Research development}

\section{Soliciting custom}

The National Research Development Corporation (NRDC) is trying to improve its image. To that end it held a meeting in Manchester last week to spread its message among leading academics, industrialists and financiers in the north-west. The meeting was the second of its kind, the first having been held in Cambridge about a year ago, and it is unlikely to be the last.

NRDC, which exists to help exploit technological innovation in industry, clearly believes that not enough demands are being made on its funds and services and that more universities, and especially industries, should be coming to it with their ideas. It supports fewer projects in relation to the number of higher education and research establishments and industries in the north-west than in any other region hence the choice of last week's meeting venue.

To judge from their criticisms, however, few of those involved in the business of technological innovation regard NRDC as a particularly helpful body. Many academics, who are obliged to of fer NRDC first refusal of inventions resulting from publicly funded research, say that it is too bureaucratic, especially in securing legal protection for non-patentable inventions such as computer software. It is also criticized for not being sufficiently aggressive in marketing inventions, and for taking both too few and too many risks. Its high failure rate, as much as 80 per cent in some fields, can be taken either as a healthy 
sign of its willingness to take risks or as a reluctance to match its patent portfolio to its financial resources.

Most of the inventions communicated to NRDC which later result in commercial success come from government research establishments, universities and industry. In the year up to March 1980, 1,786 inventions were communicated to NRDC, 68 patents were assigned to it, 56 licence agreements were completed and 157 development projects were set up. For those working outside industry, the corporation offers to patent ideas, put up funds for further development to the point of commercial exploitation and then licence the inventions with industry.

NRDC's aims seem laudable enough, but academics in particular feel that the practice does not match the theory. Those who have been able to approach industry directly with their inventions of ten report greater success, largely because they are able to negotiate relatively informal deals which do away with the legal wrangling often associated with NRDC negotiations. Universities have also become increasingly aware of their science and technology departments as potential revenue earners.

For industry, however, NRDC's services may seem more attractive and it was at industry that last week's conference was primarily aimed. If academics criticize NRDC for not driving hard enough to exploit ideas, the NRDC may equally accuse academics of lacking motivation. Appealing to industry itself to come forward with its own inventions might be more productive.

Judy Redfearn

\section{British technology}

\section{New direction}

The Centre for Technical Change, the technological think-tank set up in Britain last summer, has brought off a considerable coup by the appointment of Sir Bruce Williams (aged 62), Vice-Chancellor of the University of Sydney, as its first director. The appointment, announced last week, will take effect full-time when Sir Bruce bows out of his post at Sydney at the end of June, two months early.

The centre was set up with a grant of $£ 1.5$ million from the Leverhulme Trust and with the promise of further substantial funds (up to a total of $£ 2.25$ million over five years) from the Science and Social Science Research Councils. Its origins lie in the conviction of its sponsors that pure reason may help to explain the poor industrial performance of the United Kingdom in recent decades, especially in the exploitation of technical innovation.

One of the ironies of Sir Bruce Williams's appointment is that it is almost exactly 25 years since the appearance of a report on the same set of problems produced under the title Science and Industry by Williams and $\operatorname{Dr}$ (now also Sir) Charles Carter, recently retired Vice-
Chancellor of the University of Lancaster and now director of research at the Policy Studies Institute, London. That document raised the question of why Britain, one of the principal spenders on research and development, should apparently derive so little benefit as a consequence.

Detailed planning of the centre's work is still incomplete. It has however been decided that the centre should be based in London, not (as some had hoped) in a university town.

It was also announced last week that the deputy director of the centre will be Dr A.J. Kennedy, research director of Delta Metal Company Limited. Dr Kennedy, who is 59,

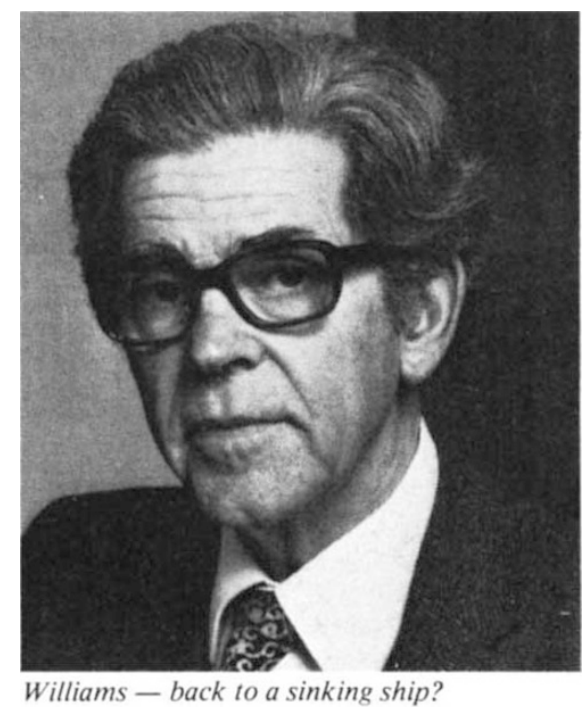

has a background in academic life (Cranfield) and in industrial research. The centre is managed by a council whose chairman is Lord (formerly Sir Michael) Swann, now Provost of Oriel College, Oxford. Its future is for the time being assured only for five years, but it is hoped that it will be able to recruit extra funds during that period and also to persuade its sponsors that it deserves a longer life.

\section{Latin America}

\section{Freedom lost}

\section{Washington}

As one of a set of new initiatives designed to help persecuted scientists in Latin America, officials of the American Association for the Advancement of Science (AAAS) intend to monitor loans provided by international development banks to research and training institutions in the subcontinent.

This action is a response to evidence presented to a workshop held during AAAS's annual meeting in Toronto last week that several loans may have been granted to Latin American institutions to compensate for the loss of scientists who have fled abroad.

There was particular concern over two loans - \$66 million lent to Argentina in 1979 by the Inter-American Development Bank (part of the World Bank) to train scientific and technological research workers at nine regional institutes, and a $\$ 32.5$ million loan last autumn to the University of Uruguay.

According to participants at the meeting, one of the purposes of the Uruguayan loan is to employ foreign faculty and consultants on a temporary basis. These workers would help to rebuild science programmes, particularly in agricultural research, that had disintegrated following the recent wave of political repression, when many university teachers had been imprisoned or had left.

The workshop recommended that scientific organizations should encourage international lending institutions to consider human rights when granting loans to educational and scientific institutions. They stressed the need to establish beyond doubt that scientific and academic freedom would be preserved.

The workshop's recommendations were made in the light of evidence that the repression of scientists in particular - and educationists in general - is becoming a chronic problem in many Latin American countries.

Several participants admitted that the situation in some of the countries had improved slightly in the past few years. There are fewer reports of repression from Brazil and Chile than in the early 1970s, and even in Argentina - Buenos Aires physicist Dr José Westerkamp said things were no worse than in the past.

But Dr Westerkamp added that there was still widespread fear that the repression might come back again. And AAAS's Committee on Scientific Freedom and Responsibility, which sponsored last week's workshop, has turned its attention to countries such as El Salvador and Guatemala, citing evidence of "generalized violence" against university and other teachers.

The evidence presented of a general decline of academic and scientific freedom in Latin American countries, including the dismissal of many scientists from teaching and research posts, was sufficient to persuade the AAAS Council, meeting last week to call for "the exploration of new initiatives to protect scientists".

One of these initiatives is likely to be the setting up of a Latin America Regional Centre for Human Rights - possibly in Venezuela - to monitor the state of scientific and academic freedom in the subcontinent, since several participants stressed the need to involve indigenous scientific societies.

Meanwhile AAAS officials said that the association hoped to invite officials from the Inter-American Development Bank to a meeting of its scientific freedom committee, and pointed to the success of international conservation groups in slowing down one loan because of its potential environmental consequences as evidence that bank of ficials seemed willing to discuss such issues.

David Dickson 